\title{
Small-Strain Dynamic Properties of Lean Cemented Sand and Gravel Materials under Different Cementing Agent Contents
}

\author{
Jie Yang, ${ }^{1,2}$ Xin Cai $\mathbb{D},{ }^{2,3}$ Yangong Shan, ${ }^{4}$ Miaomiao Yang, ${ }^{1}$ Xingwen Guo, ${ }^{3}$ and Jinlei Zhao ${ }^{5}$ \\ ${ }^{1}$ School of Transportation and Civil Engineering, Nantong University, Nantong 226019, China \\ ${ }^{2}$ State Key Laboratory of Hydrology-Water Resources and Hydraulic Engineering, Hohai University, Nanjing 210098, China \\ ${ }^{3}$ College of Mechanics and Materials, Hohai University, Nanjing 210098, China \\ ${ }^{4}$ Nanjing Branch of Jiangsu Province Hydrology and Water Resources Investigation Bureau, Nanjing 210008, China \\ ${ }^{5}$ Jiangsu Surveying and Design Institute of Water Resources Co., Ltd., Yangzhou 225127, China \\ Correspondence should be addressed to Xin Cai; xcai@hhu.edu.cn
}

Received 28 May 2020; Revised 23 September 2020; Accepted 4 November 2020; Published 24 November 2020

Academic Editor: Abdul Aziz Bin Abdul Samad

Copyright ( 92020 Jie Yang et al. This is an open access article distributed under the Creative Commons Attribution License, which permits unrestricted use, distribution, and reproduction in any medium, provided the original work is properly cited.

Lean cemented sand and gravel (LCSG) materials are increasingly being used in dams, embankments, and other civil engineering applications. Therefore, their mechanical properties and stress-strain behavior should be systematically understood. In this study, the small-strain dynamic properties of LCSG materials were examined. A series of dynamic triaxial tests were performed to investigate the effects of the confining pressure and cementing agent content of the material on its dynamic shear modulus $\left(G_{\mathrm{d}}\right)$ and damping ratio $(\lambda)$. The results show that $G_{\mathrm{d}}$ increased and $\lambda$ decreased with increasing confining pressure and cementing agent content; however, under the same confining pressure and cementing agent content, $G_{\mathrm{d}}$ decreased gradually in accordance with shear strain. Furthermore, new expressions were derived for $G_{\mathrm{d}}$ and $\lambda$, as well as for their maxima. The results of this study could provide a reference for practical engineering applications, including the construction of dams using LCSG materials.

\section{Introduction}

Lean cemented sand and gravel (LCSG) dams are structures that originated in the 1970s and exploit the advantages of both concrete-faced rockfill and roller-compacted concrete dams [1]. The cross section of an LCSG dam typically has a trapezoidal shape. Unlike a concrete-faced rockfill and roller-compacted concrete dams, the LCSG dams have many advantages, such as a significantly smaller volume and temporary flooding of the dam during the construction period. Additionally, partitioning is almost never a concern and it completely utilizes the sandy gravel in the riverbed, excavation materials, and discarded stones, which is conducive to environmental protection. Furthermore, the basis values for the strength requirements of such dams are lower, and controlling the temperature of the LCSG material is not required. In recent years, the number of LCSG dam projects has increased. While some of these dams have only been employed temporarily, LCSG dams have also been employed in several permanent projects [2]. The safety requirements for these structures are continually evolving. Similar to conventional materials, LCSG materials consist of sand, gravel, cement, and water, among other materials. However, their cement content is generally lower than $100 \mathrm{~kg} / \mathrm{m}^{3}$, whereas that in a conventional concrete or roller-compacted concrete dam is generally higher than $100 \mathrm{~kg} / \mathrm{m}^{3}$. Moreover, natural aggregate gradation is generally adopted, which is less rigid than the aggregate gradation for concrete. Thus, the LCSG material is essentially concrete with a small amount of cement.

Owing to the LCSG material composition and in order to accurately determine its stress and strain behavior in dam applications, the mechanical properties of the material should be systematically studied. Studies on the compressive strength, tensile strength, Poisson's ratio, and elastic modulus of the LCSG material have evaluated the effects of the cementing agent content, sand content, water-cement ratio, aggregate grading, and curing age via static unconfined tests 
$[3,4]$. In addition, static triaxial tests have been conducted to evaluate the various mechanical properties of the LCSG material and its similar materials, such as artificially cemented sand grains under different confining pressures, curing ages, and cementing agent contents [5-13].

At present, most practical projects using LCSG materials for dams in China are being conducted in the areas of Sichuan Province, Guizhou Province, and other parts of southwest China, where earthquakes occur frequently [2]. In order to facilitate the use of LCSG materials in such regions, their dynamic mechanical properties should be investigated. Indeed, studies concerning the dynamic mechanical properties of the LCSG material are underreported in comparison with those of their static counterparts. Determining the dynamic parameters, such as shear modulus $\left(G_{\mathrm{d}}\right)$ and damping ratio $(\lambda)$, of the materials used in civil engineering projects in the small-strain range is essential to evaluate the safety of these projects subjected to vibration or located in earthquake-prone regions. $G_{\mathrm{d}}$ and $\lambda$ of some materials, including granular soil and cement-treated clay, and many other materials, have been studied extensively in previous works [14-25]. Clayton and Heymann [14] presented the triaxial tests of some natural geomaterials and provided stiffness at very small strains under the assumption of isotropy. Liu et al. [15] presented some shear wave velocity tests of pure sand, gravel, and a sand-gravel mixture under isotropic confining pressures to investigate the effect of mean particle size $\left(D_{50}\right)$ on the small-strain shear modulus. Their results showed that the small-strain shear modulus is insensitive to $D_{50}$ for poorly graded soils but increases with $D_{50}$ for well-graded soils. Bayat and Ghalandarzadeh [16] acquired resonant column testing, bender element testing, and cyclic triaxial testing results and studied the effect of gravel content on $G_{\mathrm{d}}$ and $\lambda$. Li et al. [17] conducted resonant column tests to investigate $G_{\mathrm{d}}$ and $\lambda$ of the steel slag sand mixture (SSM) and cement sand mixture (CSM) and explored the effects of confining pressure, mix proportion, and curing age on these dynamic parameters. They concluded that the mix proportion was the most significant factor. Subramaniam et al. [18] presented a hyperbolic model-based normalized shear modulus reduction formulation, which assumed that the cemented clay follows the failure pattern of the modified structured Cam-Clay model, and established a reliable damping ratio model based on the Masing rule by a correction factor. Lang et al. [19] quantitatively analyzed the shear moduli and damping ratios of materials similar to the LCSG material, such as cement-stabilized silty clay and fly ash-stabilized silty clay. Most previous works on the dynamic properties of these materials focused on the isotropic stress conditions. However, soils in Earth structures, including natural soils under slopes and some dam materials, were invariably subjected to anisotropic stress conditions. Wang and Mok [20] used true triaxial tests and the corresponding numerical simulations using the discrete element method (DEM) to investigate the stress- and fabricinduced small-strain shear stiffness anisotropy of soils. Their results showed that the effect of strong forces on the fabricinduced stiffness anisotropy was greater than that of weak forces. Payan et al. [21] conducted a triaxial test of sand under isotropic and anisotropic loading conditions and showed that the small-strain shear modulus under anisotropic loading was greater than that subjected to isotropic stress. Yao et al. [22] proposed a framework for describing the modulus degradation behavior of cement-treated soft clay considering the effect of the mix ratio. Furthermore, they established a conceptual framework for describing the small-strain shear modulus of cement-treated clay under the influence of different factors, such as mix ratio, curing time, void ratio, stress state, over consolidation, and yielding [23]. Bayat and Ghalandarzadeh [24] investigated the effects of depositional method, mean effective consolidation stress, shear strain amplitude, and relative density on $G_{\mathrm{d}}$ and $\lambda$ of pure sand, gravel, and sand-gravel mixtures. They showed that the depositional method had a significant effect on the dynamic shear modulus, but not on the shear modulus at large shear strain amplitudes, and the effects of the depositional method on the small-strain dynamic properties were dependent on an effective confining pressure and relative density. They also proposed a new modified empirical model to estimate $G_{\mathrm{d}}$ and $\lambda$ under different mean effective consolidation stresses, consolidation stress ratios, and gravel contents [25]. Nevertheless, the composition of these materials is slightly different from that of the LCSG material; their quantitative expressions cannot be directly used to reflect the small-strain dynamic performance of the LCSG material. Based on research methods for determining the dynamic characteristics of conventional gravel stone, Omae et al. [26] used a dynamic triaxial apparatus to test the dynamic properties of the LCSG material with a certain cementing agent content. The results showed that the dynamic shear modulus of the LCSG material increased with increasing confining pressure under a small amount of circulating pressure. Additionally, it was determined that the dynamic stress-strain relationship of the LCSG material exhibited clear nonlinear characteristics. Kondner's hyperbolic model can also be used to describe the dynamic characteristics of the LCSG material [27]. Some studies on the static characteristics of LCSG materials show that the cementing agent content is one of the most important factors when working with LCSG materials [5-12]. Regarding the effects of the cementing agent content, Fu et al. $[28,29]$ preliminarily reported the dynamic shear modulus, damping ratio, and residual deformation of the LCSG material under anisotropic stress conditions.

In the existing literature, the dynamic characteristics of lean cemented sand and gravel (LCSG) material are only preliminarily discussed in terms of the shear modulus and damping ratio under different cementing agent contents. The quantitative relationship between shear modulus, damping ratio, and the cementing agent content is not stated, which means that the small-strain dynamic properties of LCSG materials are still not completely known. In this study, we propose and examine an approach to determine the small-strain dynamic properties of LCSG material specimens using cyclic triaxial tests under different cementing agent contents and varying confining pressures under anisotropic stress conditions. The small-strain dynamic properties examined include the dynamic shear 
modulus $G_{\mathrm{d}}$ and damping ratio $\lambda$. Quantitative expressions for $G_{\mathrm{d}}$ and $\lambda$ are also proposed taking into consideration the effects of the cementing agent content and confining pressure, which make also the proposed expressions suitable for coarse-grained soil.

\section{Materials and Methods}

2.1. Raw Material, Mix Design, and Testing Program. In order to achieve a complete and systematic understanding of the small-strain dynamic properties of the LCSG material, we used the following raw materials to create the LCSG specimens: cement (P.C. 32.5), crushed stone, sand, and water. The raw materials used in this study are the same as those used in previous LCSG static triaxial tests $[11,12]$. In order to explore the effect of different cementing agent contents on the small-strain dynamic properties of the LCSG material, we evaluated cement agent contents of 40,60 , and $80 \mathrm{~kg} / \mathrm{m}^{3}$, which are the amounts commonly used in some LCSG dams [2]. The mix designs are listed in Table 1. In accordance with the technical guideline for LCSG dams [30], the water-cement ratio used in the tests performed for this study was consistently maintained at 1.0. The relative density of LCSG material is 2.21 .

2.2. Sample Preparation. The LCSG specimens used in the dynamic cyclic triaxial tests were prepared and tested according to the relevant standards outlined in SL237-1999 [31]. The specimens were cylindrical in shape with a diameter of $300 \mathrm{~mm}$ and a height of $700 \mathrm{~mm}$. The following process was used to prepare the specimens. The process was the same as those used for the specimens in previous static triaxial tests.

The cement, coarse, and fine aggregates (Figure 1) and water were mixed according to the desired composition of the LCSG specimens detailed in Table 1. The LCSG material mix was placed in a cylindrical mold in five layers. Each layer was compacted via vibration (Figure 2(a)) and then ground down to form the specimens. The specimens were cured in a laboratory at $20 \pm 2^{\circ} \mathrm{C}$ for 28 days. To improve the accuracy of the results, two specimens of each mix type were tested under a specific confining pressure. The samples were securely covered with rubber sleeves to prevent damage from any particles that may fall from the specimens (Figure 2(b)).

2.3. Test Apparatus. Dynamic triaxial tests of the LCSG specimens were conducted using a TYD-1500 dynamic triaxial tester. This tester has a comprehensive precision index better than $1 \%$, maximum confining pressure capability of $4.0 \mathrm{MPa}$, maximum axial load of $1500 \mathrm{kN}$, maximum axial vibration load of $500 \mathrm{kN}$, and vibration frequency range of $0.01-5 \mathrm{~Hz}$. The test parameters of the tester were confirmed to be suitable for the LCSG material. The small stains are measured by using Linear Variable Differential Transformers (LVDT) [14].

For large-scale triaxial shear tests of the LCSG specimens, particularly for those with high cementing agent contents, the prepared specimens were first covered with rubber membranes before being mounted on the test instrument. The specimens were then saturated using the hydrostatic head test method. The consolidation stress ratio $K$ was set to 2.0 for the consolidation of the specimens at mean effective confining pressures of 300,600, 900, and $1200 \mathrm{kPa}$ as the study aims to investigate the dynamic shear modulus and damping ratio under those confining pressures, which can be applied to simulate the working conditions of 100 meters high LCSG dams. Next, a cyclic load was applied in the axial direction of each specimen. The vibration waveforms were sinusoidal, and the excitation frequency was $0.3 \mathrm{~Hz}$, based on relevant test manuals and reports $[32,33]$. Each specimen was subjected to 12 stages of dynamic loadings, with three cycles in each stage.

Based on the results of the dynamic triaxial tests of the LCSG specimens with varying cementing agent contents under various mean effective confining pressures, the trunk curve for the relationship between the dynamic shear stress, $\tau_{\mathrm{d}}$, and the dynamic shear strain, $\gamma_{\mathrm{d}}$, was obtained as shown in Figure 3. The dynamic shear modulus, $G_{\mathrm{d}}$, which is directly expressed by the equivalent shear modulus, $G_{\text {eq }}$, is also presented and defined by the following expression [33]:

$$
G_{\mathrm{d}}=G_{\mathrm{eq}}=\frac{\tau_{\mathrm{d}}}{\gamma_{\mathrm{d}}} \text {. }
$$

Figure 4 depicts a single cyclic stress-strain hysteretic cycle obtained from the dynamic triaxial tests [34]. The point $O$ denotes the center of the hysteresis loop, and the backbone curve for the relationship between $\tau_{\mathrm{d}}$ and $\gamma_{\mathrm{d}}$ goes through point $O$. The damping ratio, $\lambda$, which is directly expressed by the equivalent damping ratio $\lambda_{\text {ep }}$, is defined using the following expression [33]:

$$
\lambda=\lambda_{\mathrm{ep}}=\frac{1}{4 \pi} \frac{A_{L}}{A_{T}},
$$

where $A_{L}$ is the area of the single cyclic stress-strain hysteretic cycle and $A_{T}$ is the area of triangle $\mathrm{OAH}$.

\section{Results and Analysis}

3.1. Small-Strain Dynamic Shear Modulus. Figure 5 shows the effect of the mean effective confining pressure on the variation in $G_{\mathrm{d}}$ with $\gamma_{\mathrm{d}}$ for the LCSG material. It is observed that $G_{\mathrm{d}}$ increases with increasing mean effective confining pressure, which is the same behavior as the variation in $G_{\mathrm{d}}$ with mean effective confining pressure for granular soils and cement-treated clay. This occurs because the increase in the mean effective confining pressure compresses the voids between the coarse and fine aggregate particles, thereby increasing the compaction degree of the sample, which, in turn, increases $G_{\mathrm{d}}$. As the cyclic loading accumulates, the internal structure of the sample loosens, manifesting as a nonlinear decrease in $G_{\mathrm{d}}$ with $\gamma_{\mathrm{d}}$. That is, the $G_{\mathrm{d}-\gamma \mathrm{d}}$ curves of the LCSG material can be described in two stages: gradual decrease and rapid decrease, but there is an unremarkable transition between the two stages, which is different from the two-stage variations in $G_{\mathrm{d}}$ with $\gamma_{\mathrm{d}}$ observed for cementstabilized silty clay (CSC), cement and fly ash-stabilized silty 
TABLE 1: Details of the test specimens.

\begin{tabular}{|c|c|c|c|c|c|}
\hline \multirow{2}{*}{ ID } & \multirow{2}{*}{ Cement $\left(\mathrm{kg} / \mathrm{m}^{3}\right)$} & \multirow{2}{*}{ Sand $\left(\mathrm{kg} / \mathrm{m}^{3}\right)$} & \multicolumn{3}{|c|}{ Crushed stone $\left(\mathrm{kg} / \mathrm{m}^{3}\right)$} \\
\hline & & & 5-10 (mm) & $10-20(\mathrm{~mm})$ & $20-40(\mathrm{~mm})$ \\
\hline 1 & 40 & 477 & 340.8 & 596.4 & 715.7 \\
\hline 2 & 60 & 477 & 340.8 & 596.4 & 715.7 \\
\hline 3 & 80 & 477 & 340.8 & 596.4 & 715.7 \\
\hline
\end{tabular}

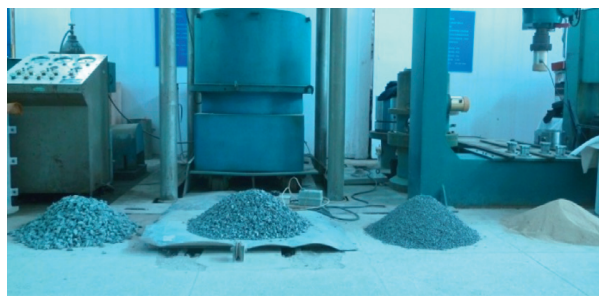

FIgURE 1: Crushed stone and sand.

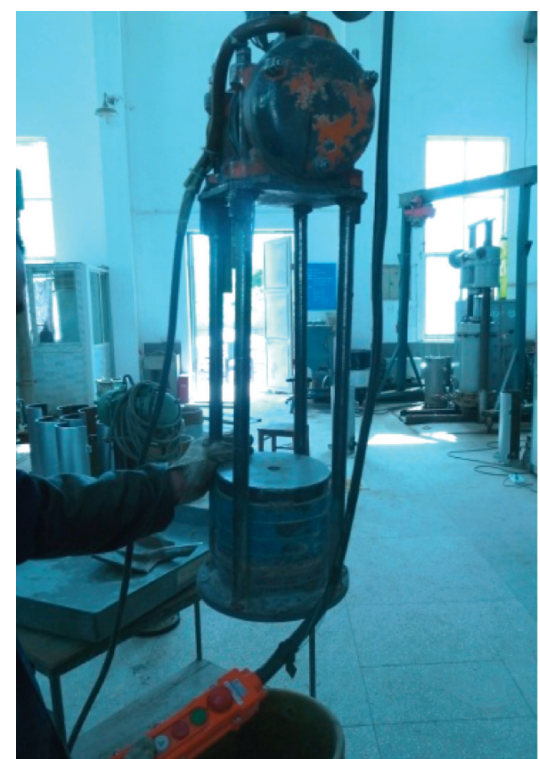

(a)

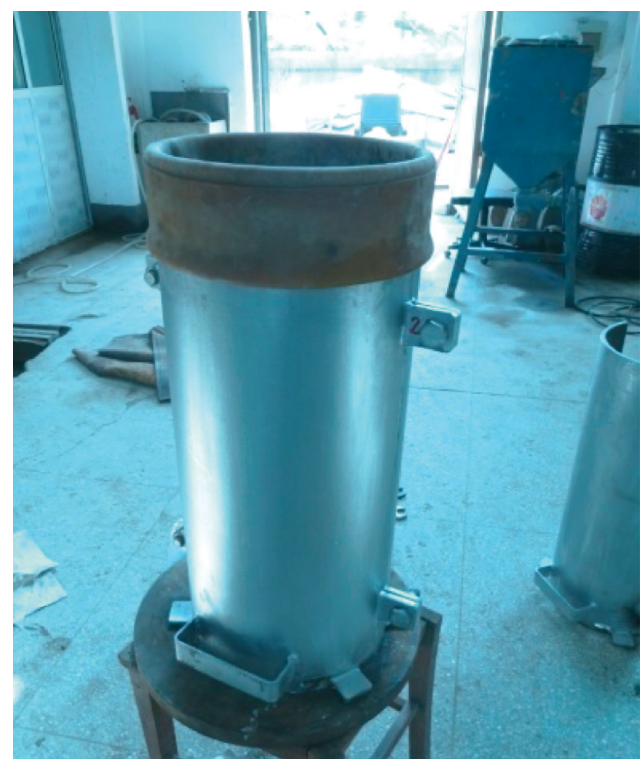

(b)

Figure 2: Equipment for specimen preparation. (a) High-frequency vibration roller. (b) Ductile iron mold.

clay (CFSC), and some other soils (i.e., gradual decrease and rapid decrease, with a noticeable transition between stages) $[16-19,24,25,35-38]$. This could be due to the material compositions of the LCSG material.

Figure 5 also shows the effect of the cementing agent content on the variation in $G_{\mathrm{d}}$ with $\gamma_{\mathrm{d}}$. When the confining pressure and shear strain are constant, it is observed that $G_{\mathrm{d}}$ increases with increasing cementing agent content, which is similar to the effect of cementing agent content on the shear modulus of cement-treated clay. It is well known that cement has good potential for pozzolanic activity, producing additional hydration products and improving the cementation of the LCSG material and cement-treated clay [17-19]. It is conducive to an increase in strength and dynamic shear modulus $G_{\mathrm{d}}$ development.
3.2. Expression for the Dynamic Shear Modulus. As observed from the variation in $G_{\mathrm{d}}$ with $\gamma_{\mathrm{d}}$ shown in Figure 5, the maximum level of $G_{\mathrm{d}}$ is at a strain value of $10^{-3}$, and then the $G_{\mathrm{d}}$ value decreases nonlinearly with the continued increase in $\gamma_{\mathrm{d}}$. The relationship between $G_{\mathrm{d}}$ and $\gamma_{\mathrm{d}}$ in the LCSG material is accordingly fitted to express the dynamic shear modulus, $G_{\mathrm{d}}$, using the Hardin-Drevich (H-D) model [39] as follows:

$$
\frac{G_{\mathrm{d}}}{G_{\mathrm{d}}^{\max }}=\frac{1}{1+\left(\gamma_{\mathrm{d}} / \gamma_{r}\right)},
$$

where $G_{\mathrm{d}} / G_{\mathrm{d}}^{\max }$ is the normalized dynamic shear modulus and $\gamma_{\mathrm{d}}$ and $\gamma_{r}$ are the shear strain and reference shear strain, respectively. The reference shear strain, $\gamma_{r}$, is used as a 


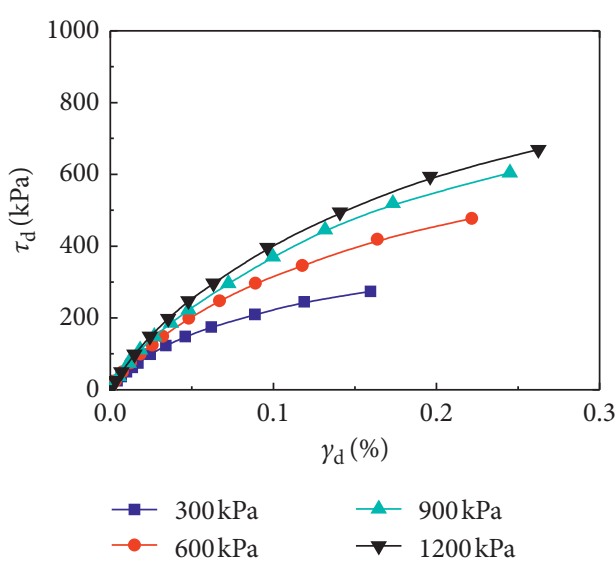

(a)

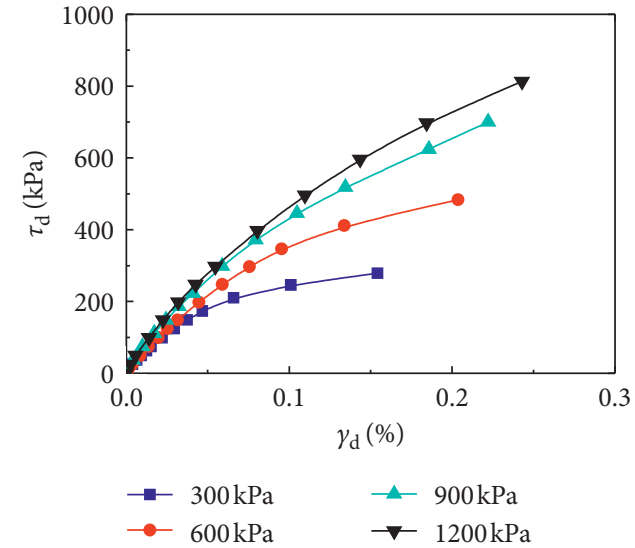

(b)

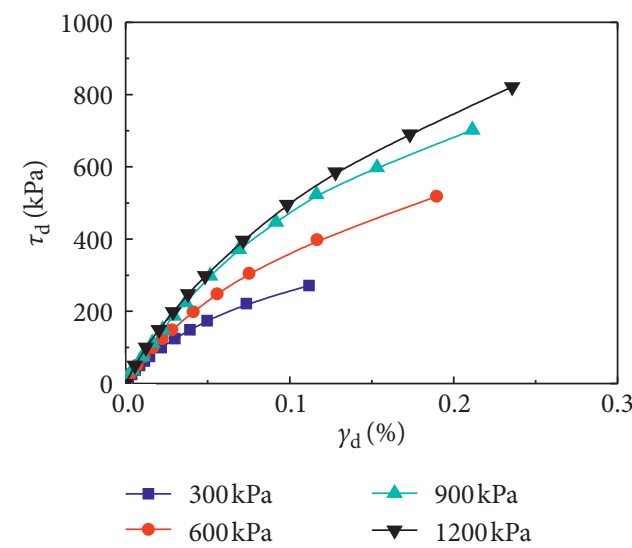

(c)

FIgURE 3: Backbone curve under different LCSG material cementing agent contents. (a) $40 \mathrm{~kg} / \mathrm{m}^{3}$. (b) $60 \mathrm{~kg} / \mathrm{m}^{3}$. (c) $80 \mathrm{~kg} / \mathrm{m}^{3}$.

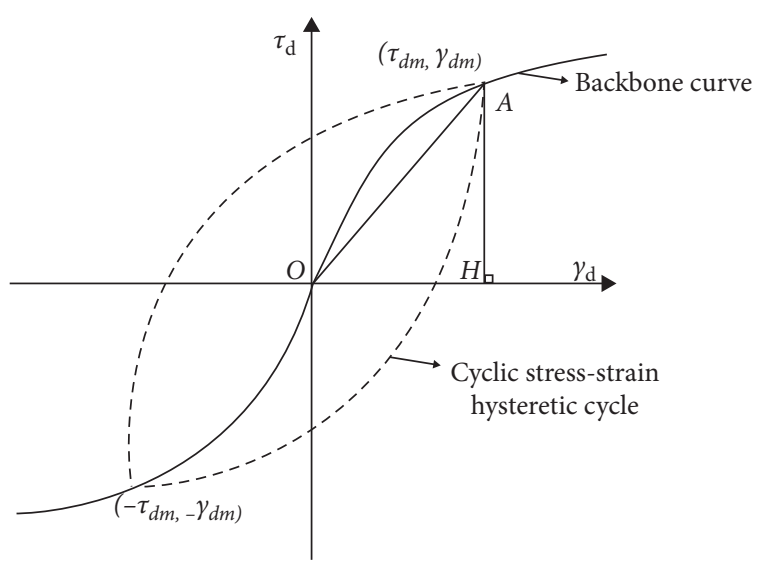

FIGURE 4: Single cyclic stress-strain hysteretic cycle.

curvature parameter to describe the variation in the curve fitting and is determined by

$$
\gamma_{r}=\frac{\tau_{\mathrm{d}}^{\max }}{G_{\mathrm{d}}^{\max }}
$$

where $\tau_{\mathrm{d}}^{\max }$ is the maximum dynamic shear stress.
The backbone curves for the relationship between $G_{\mathrm{d}}$ and $\gamma_{\mathrm{d}}$ in the Hardin-Drevich (H-D) model can be expressed by

$$
\frac{1}{G_{\mathrm{d}}}=\frac{1}{G_{\mathrm{d}}^{\max }}+\frac{\gamma_{\mathrm{d}}}{\tau_{\mathrm{d}}^{\max }}
$$

Figure 6 shows that the relationship between $G_{\mathrm{d}}$ and $\gamma_{\mathrm{d}}$ is approximately linear, except for a slightly curved behavior near shear strain $10^{-3}$. The relationship in Figure 6 can be obtained using equation (5). It is worth noting that the intercept of these lines is the reciprocal of $G_{\max }$ and that the slope is the reciprocal of $\tau_{\mathrm{d}}^{\max }$. Thus, in this study, although the relationship curve between the shear modulus and the dynamic strain of the LCSG material shows an unremarkable transition between the two stages, the relationship between $G_{\mathrm{d}}$ and $\gamma_{\mathrm{d}}$ can still be simulated with the classical $\mathrm{H}-\mathrm{D}$ model, which is commonly used for coarse-grained soils.

Figure 7 illustrates the typical relationship between $G_{\mathrm{d}}^{\max }$ and the mean effective confining pressure of the LCSG material for different cementing agent contents. Evidently, $G_{\mathrm{d}}^{\max }$ increases with increasing mean effective confining pressure; however, this increase becomes gradually less significant, which is different from the linear relationship between $G_{\mathrm{d}}^{\max }$ and the mean effective confining pressure of 


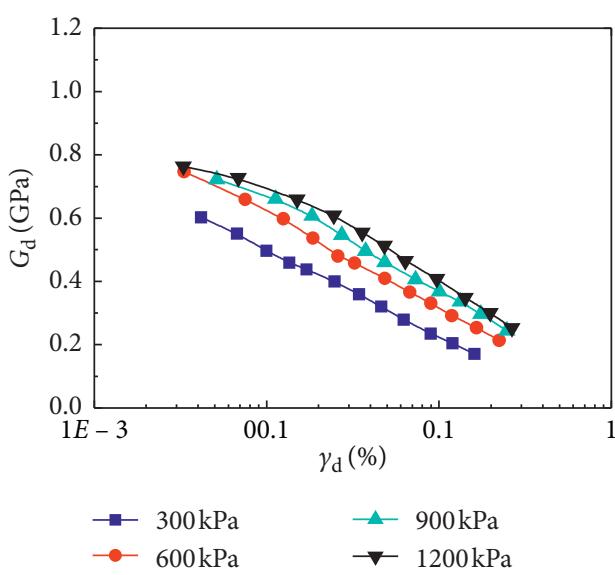

(a)

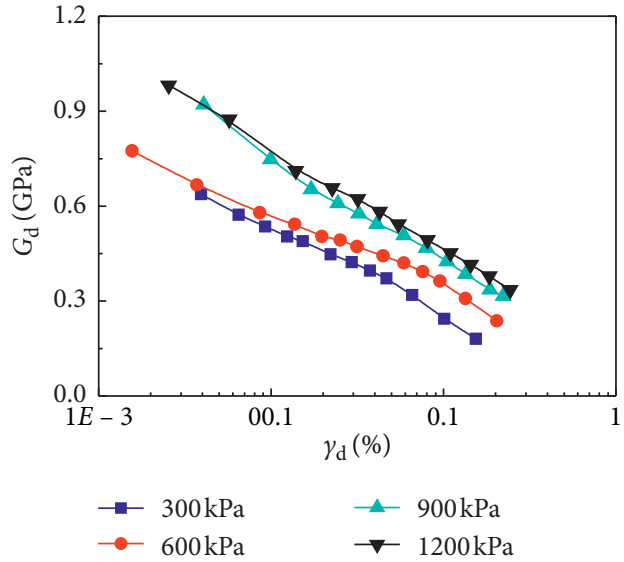

(b)

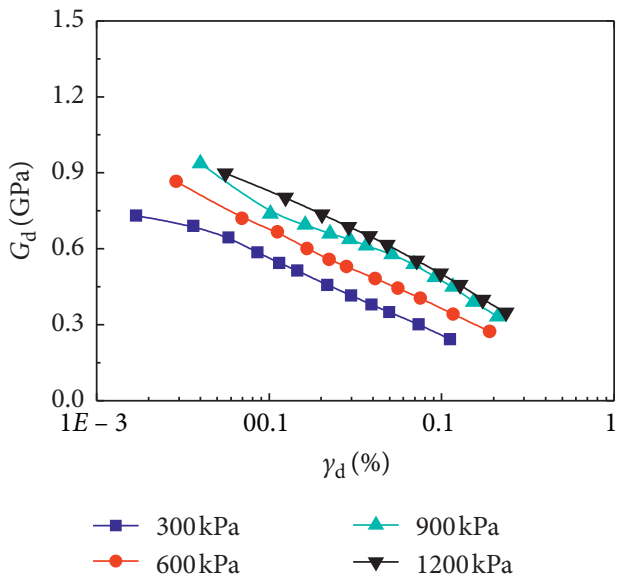

(c)

Figure 5: Shear modulus $G_{\mathrm{d}}$ of the LCSG material under different cementing agent contents and according to changes in dynamic shear strain. (a) $40 \mathrm{~kg} / \mathrm{m}^{3}$. (b) $60 \mathrm{~kg} / \mathrm{m}^{3}$. (c) $80 \mathrm{~kg} / \mathrm{m}^{3}$.

SSM and CSM [17], similar with coarse-grained soils $[15,25]$. Similarly, $G_{\mathrm{d}}^{\mathrm{max}}$ of the LCSG material also increases with increasing cementing agent content. These observations imply that increasing the mean effective confining pressure results in an evident improvement in the development of $G_{\mathrm{d}}^{\max }$. This trend is different from the approximate linearity of $G_{\max }$ changes with increasing confining pressure of steel slag sand mixture and cement sand mixture, but that is still observed in the test results of other similar materials, such as cement-stabilized silty clay (CSC) and cement-fly ash-stabilized silty clay (CFSC) [19]. The possible reason is that the range of confining pressure is smaller than that of LCSG material, and if several tests under confining pressures greater than $150 \mathrm{kPa}$ are added, the nonlinear curve may be more applicable for steel slag sand mixture and cement sand mixture than the linear curve. In addition, these results are also consistent with the relationship observed in previous studies between the static initial modulus of the LCSG material and granular soil and confining pressure. Similar to the relation between $G_{\mathrm{d}}^{\max }$ and $\sigma_{3}$ of granular soil when the void ratio is constant $[15,25]$, the relationship between the maximum shear modulus $G_{\mathrm{d}}^{\max }$ and the mean effective confining pressure $\sigma_{3}$ of the LCSG material is defined as follows:

$$
G_{\mathrm{d}}^{\max }=k^{\prime} \cdot \mathrm{Pa}\left(\frac{\sigma_{3}}{\mathrm{~Pa}}\right)^{n}
$$

where $k^{\prime}$ is a dimensionless parameter related to the material type, the atmospheric pressure $\mathrm{Pa}$ is $100 \mathrm{kPa}, k^{\prime} \cdot \mathrm{Pa}$ represents the maximum shear modulus when the confining pressure is $100 \mathrm{kPa}$, and $n$ represents the growth index of the maximum shear modulus.

The values of $k^{\prime}$ and $n$ were obtained through an analysis of the data presented in Figure 7 and equation (6) and are listed in Table 2 . The correlation coefficients, $R^{2}$, in the table are all greater than 0.99, indicating that the calculated results of equation (6) appear to largely fit the corresponding test results. However, when $\sigma_{3}$ approaches zero, $G_{\mathrm{d}}^{\max }$ in equation (6) is also zero, which is inconsistent with the actual value for the LCSG material under this condition. Thus, similar to the static initial modulus explained by Yang et al. [12], the relationship between $G_{\mathrm{d}}^{\max }$ and $\sigma_{3}$ for the LCSG material in this study can be expressed as follows: 


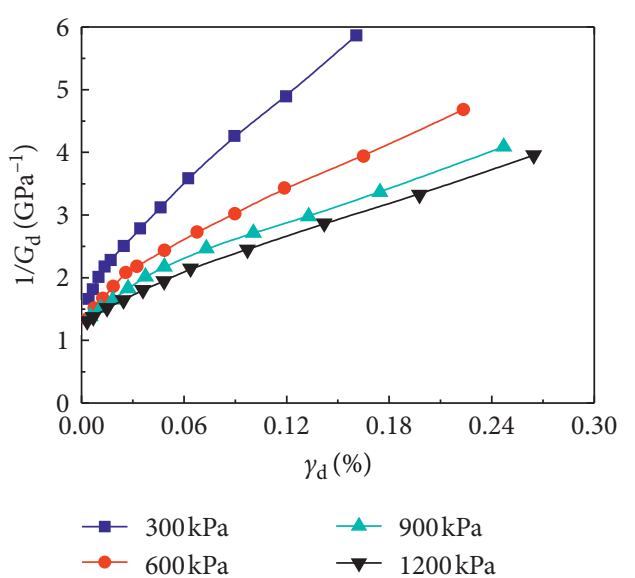

(a)

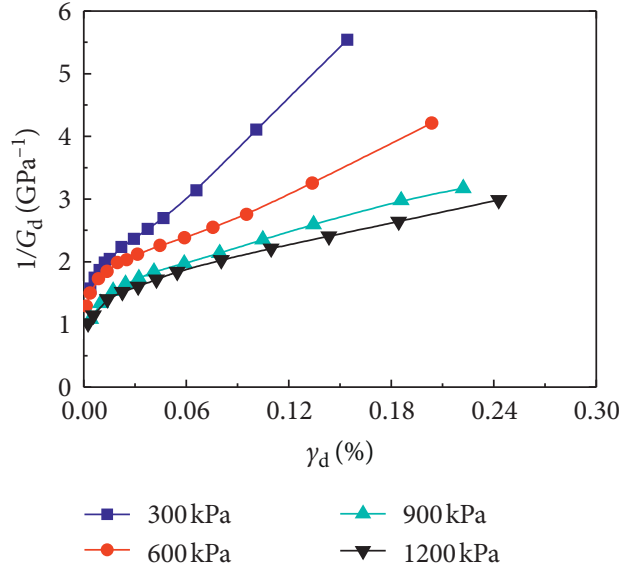

(b)

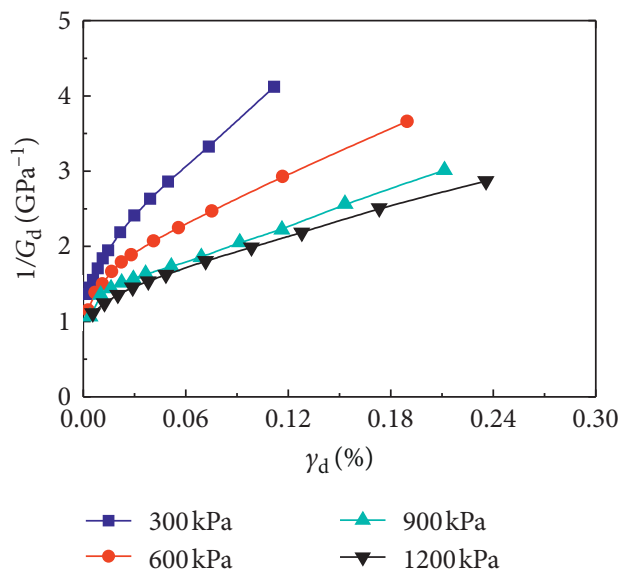

(c)

FIGURE 6: Shear moduli $G_{\mathrm{d}}$ of the LCSG material under different cementing agent contents and according to changes in dynamic shear strain. (a) $40 \mathrm{~kg} / \mathrm{m}^{3}$. (b) $60 \mathrm{~kg} / \mathrm{m}^{3}$. (c) $80 \mathrm{~kg} / \mathrm{m}^{3}$.

$$
G_{\mathrm{d}}^{\max }=k \cdot \operatorname{Pa}\left(\frac{\sigma_{3}+\mathrm{Pa}}{\mathrm{Pa}}\right)^{n}
$$

where $k$ is a dimensionless parameter related to the material type, the atmospheric pressure $\mathrm{Pa}$ is $100 \mathrm{kPa}, k \cdot \mathrm{Pa}$ represents the maximum shear modulus when the mean effective confining pressure is 0 , and $n$ represents the growth index of the maximum shear modulus.

Table 3 lists the values of $k$ and $n$ for varying cementing agent contents obtained by a regression analysis of the data in Figure 7 and equation (7). The $R^{2}$ values are all greater than 0.99 , indicating that the calculated results of equation (7) fit the experimental results. Therefore, equation (7) can be confidently used to derive $G_{\mathrm{d}}^{\max }$ of the LCSG material as a function of the mean effective confining pressure under all conditions.

The test values of $k$ and $n$ for the LCSG material under varying cementing agent contents, as well as for rockfill material [38], are shown in Figures 8 and 9, respectively. As observed, with the increasing cementing agent content, $k$ increases linearly and $n$ decreases with decreasing amplitude.
In this study, $k$ and $n$ were fitted using the corresponding parameters for rockfill and the LCSG material with cementing agent contents of $40 \mathrm{~kg} / \mathrm{m}^{3}$ and $80 \mathrm{~kg} / \mathrm{m}^{3}$. Thus,

$$
\begin{aligned}
& k=k_{0}\left(\frac{C c}{C c_{0}}\right)+k_{1}, \\
& n=n_{0} e^{m\left(C c / C c_{0}\right),}
\end{aligned}
$$

where $C c$ is the cementing agent content and $k_{0}$ and $k_{1}$ are the fitting coefficients of the relationship between $k$ and $C c$. Here, $k_{0}$ represents the growth of parameter $k$ for $G_{\mathrm{d}}^{\max }$ with an increase in $C c$ and $k_{1}$ represents the value of $k$ for $G_{\max }$ when $C c$ is zero. In addition, $n_{0}$ and $m$ are the fitting coefficients of the relationship between $n$ and $C c$, where $n_{0}$ represents the value of parameter $n$ for $G_{\mathrm{d}}^{\max }$ when $C c$ is 0 and $m$ denotes the growth for $G_{\mathrm{d}}^{\max }$ with increasing $C c . C c_{0}$ is the reference cementing agent content with a value of $1 \mathrm{~kg} / \mathrm{m}^{3}$.

Equation (7) provides an expression for $G_{\mathrm{d}}^{\max }$ of the LCSG material. To verify the accuracy of this expression, the experimental results for the LCSG material with a cementing 


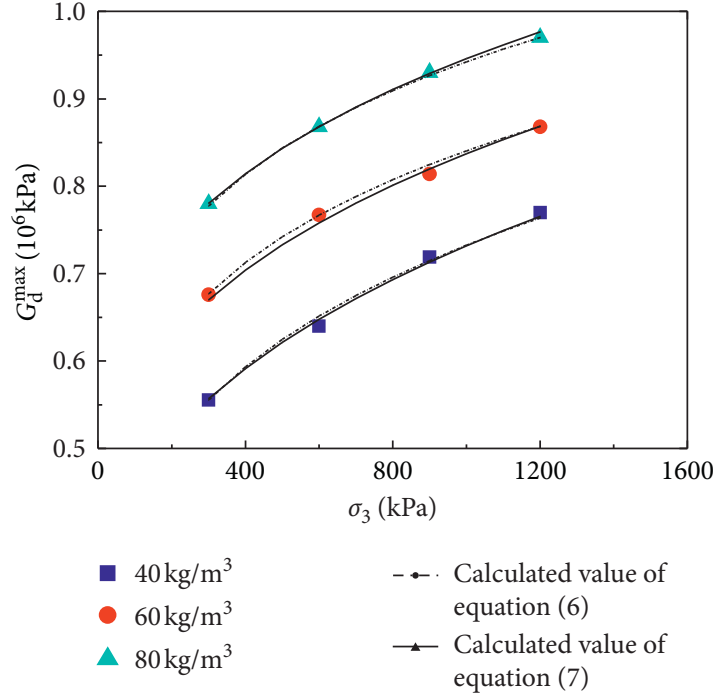

Figure 7: Relation between $G_{\mathrm{d}}^{\max }$ and $\sigma_{3}$ under different cementing agent contents.

TABle 2: Parameters $k^{\prime}$ and $n$ with varying cementing agent contents

\begin{tabular}{lccc}
\hline Cementing agent content, $C c\left(\mathrm{~kg} / \mathrm{m}^{3}\right)$ & $k^{\prime}$ & $n$ & $R^{2}$ \\
\hline 40 & 4313 & 0.23 & 0.99 \\
60 & 5553 & 0.18 & 0.99 \\
80 & 6519 & 0.16 & 0.99 \\
\hline
\end{tabular}

TABLE 3: Parameters $k$ and $n$ with varying cementing agent contents.

\begin{tabular}{lccc}
\hline Cementing agent content, $C c\left(\mathrm{~kg} / \mathrm{m}^{3}\right)$ & $k$ & $n$ & $R^{2}$ \\
\hline 40 & 3830 & 0.27 & 0.99 \\
60 & 4950 & 0.22 & 0.99 \\
80 & 5998 & 0.19 & 0.99 \\
\hline
\end{tabular}

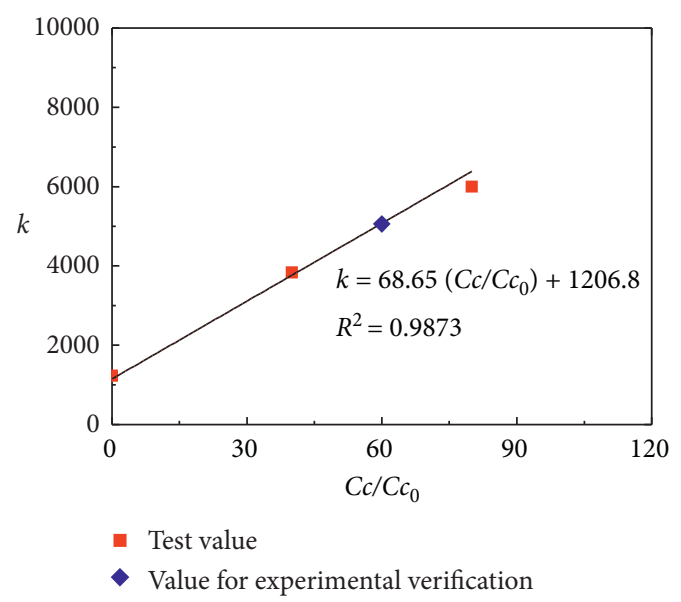

FIGURE 8: Relation between $k$ and the cementing agent contents.

agent content of $60 \mathrm{~kg} / \mathrm{m}^{3}$ were compared with the calculated results of equations (8) and (9), and are shown in Figures 8 and 9. The $R^{2}$ values in these figures are all greater

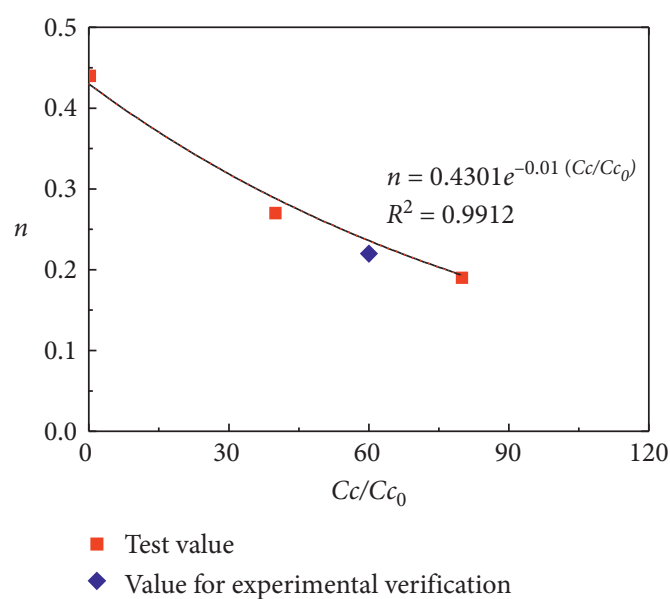

Figure 9: Relation between $n$ and the cementing agent contents.

than 0.99 , indicating that the calculated results fit the experimental results for the LCSG material. This finding confirms that these equations can be used to accurately describe parameters $k$ and $n$ for the LCSG material as functions of different cementing agent contents.

According to the backbone curves for the relationship between $G_{\mathrm{d}}$ and $\gamma$ from equation (3), the dynamic elastic modulus and dynamic shear strain of the LCSG material can be also expressed by the following formula:

$$
\frac{G_{\mathrm{d}}}{G_{\mathrm{d}}^{\max }}=\frac{1}{a \bar{\gamma}_{\mathrm{d}}+1},
$$

where $a$ is the slope of the fitting line and $\bar{\gamma}_{\mathrm{d}}$ is the normalized dynamic strain. Here, $\bar{\gamma}_{\mathrm{d}}=\gamma_{\mathrm{d}}\left(\left(\sigma_{3}+\mathrm{Pa}\right) /(\mathrm{Pa})\right)^{n-1}$ were used in this study rather than $\bar{\gamma}_{\mathrm{d}}=\gamma_{\mathrm{d}}\left(\left(\sigma_{3}\right) /(\mathrm{Pa})\right)^{n-1}$ for the LCSG material. Figure 10 shows the points $\left(G_{\mathrm{d}}^{\max } / G_{\mathrm{d}}, \bar{\gamma}_{\mathrm{d}}\right)$ as Cartesian coordinates for various mean effective confining pressures applied to the LCSG material with cementing agent contents of $40 \mathrm{~kg} / \mathrm{m}^{3}, 60 \mathrm{~kg} / \mathrm{m}^{3}$, and $80 \mathrm{~kg} /$ $\mathrm{m}^{3}$. These points, which correspond to various cementing agent contents and confining pressures, are approximately on the same line and can be expressed as

$$
\frac{G_{\mathrm{d}}^{\max }}{G_{\mathrm{d}}}=a \bar{\gamma}_{\mathrm{d}}+1
$$

where $a$ is the slope of the line.

By substituting equations (7), (8), and (9) into equation (11), the dynamic elastic modulus, $G_{\mathrm{d}}$, of the LCSG material can be obtained according to the cementing agent content and mean effective confining pressure as follows:

$$
G_{\mathrm{d}}=\frac{\left[k_{0}\left(C c / C c_{0}\right)+k_{1}\right] \cdot \mathrm{Pa}\left[\left(\sigma_{3}+\mathrm{Pa}\right) / \mathrm{Pa}\right]^{n_{0} e^{m\left(C c / c c_{0}\right)}}}{a \gamma_{\mathrm{d}}\left[\left(\sigma_{3}+\mathrm{Pa}\right) / \mathrm{Pa}\right]^{n_{0} e^{m\left(C c / C c_{0}\right)+1 .}}}
$$

In order to verify equation (12), the dynamic elastic modulus $G_{\mathrm{d}}$ of the LCSG material with a cementing agent content of $60 \mathrm{~kg} / \mathrm{m}^{3}$ was determined under different shear strains $\gamma_{\mathrm{d}}$ and mean effective confining pressures. The 


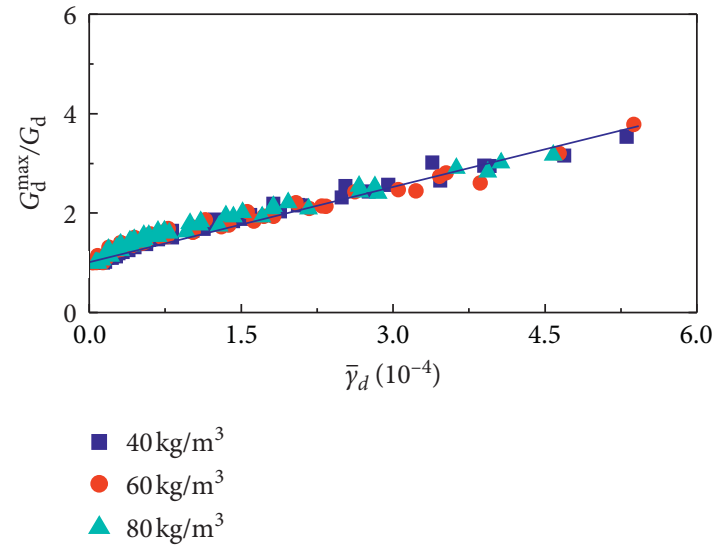

FIgURE 10: Relation between $G_{\mathrm{d}}^{\max } / G_{\mathrm{d}}$ and $\overline{\gamma_{\mathrm{d}}}$ with varying cementing agent contents.

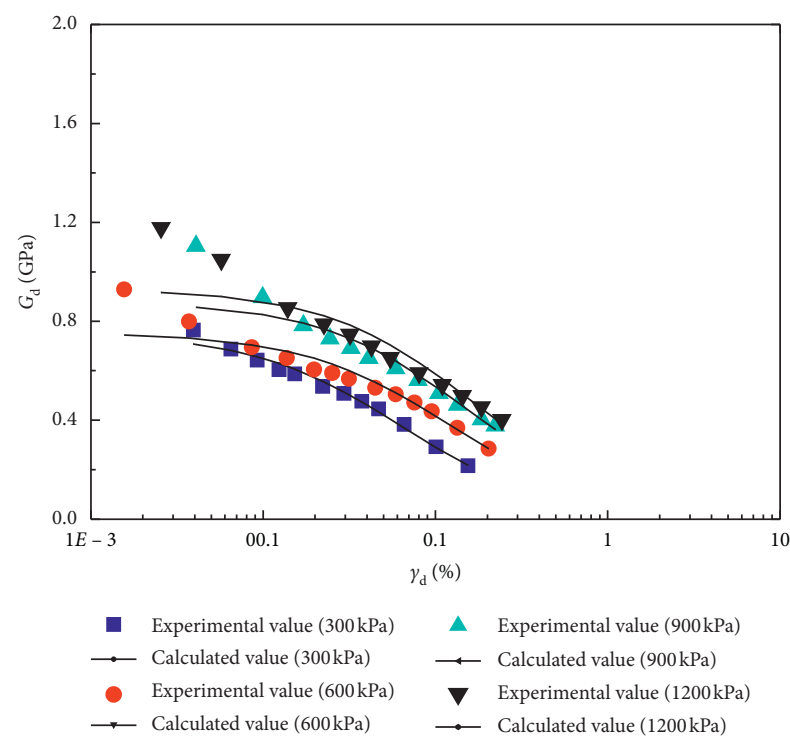

FIGURE 11: Experimental dynamic shear modulus results and their corresponding calculated values.

calculation results are shown in Figure 11. Here, the experimental results for the shear modulus at low confining pressures (300 and $600 \mathrm{kPa}$ ) are in good agreement with the corresponding calculated values. Under a high confining pressure, the experimental values of shear modulus are mostly consistent with the corresponding calculated values, whereas the calculated values with a small strain are slightly lower than the experimental results. These results show that equation (12) can effectively reflect the natural variation law of dynamic shear modulus with its corresponding shear strain, which can be different for different materials, such as granular soil and cement-treated soft clay. Equation (12) is intended to verify the rationality of the dynamic constitutive model of the LCSG material with a cementing agent content of $60 \mathrm{~kg} / \mathrm{m}^{3}$. Because the actual expression of the LCSG material with the cementing agent content and its parameters are determined based on test results for LCSG with a cementing agent content of 40 and $80 \mathrm{~kg} / \mathrm{m}^{3}$ and for rockfill, the validation also shows that equation (12) is also suitable for LCSG materials under different cementing agent contents and for coarse-grained soils.

3.3. Damping Ratio. The damping ratio, $\lambda$, of a geotechnical material reflects its energy dissipation capability under a cyclic or dynamic load. In this study, the effects of the mean effective confining pressure and cementing agent content on the variation in $\lambda$ with $\gamma_{\mathrm{d}}$ were investigated for the LCSG material.

Figure 12 shows the effects of the mean effective confining pressure on the variation in $\lambda_{\mathrm{d}}$ with $\gamma_{\mathrm{d}}$ for the LCSG material, indicating that $\lambda$ decreases with increasing mean effective confining pressure. Similar to granular soil, cementtreated clay, SSM, and CFSC $[17-19,25]$, an increase in mean effective confining pressure can be observed to increase the density of the internal structure of the material. For $\gamma_{\mathrm{d}}$ values from $10^{-3}$ to $10^{-2}, \lambda$ increases approximately linearly with $\gamma_{\mathrm{d}}$, whereas $\lambda$ increases rapidly for $\gamma_{\mathrm{d}}$ values from $10^{-2}$ to $10^{-1}$. This can be explained by the gradual destruction of the bonds between the aggregate particles, which occurs with the increase in the number and maximum value of the cyclic loads applied during the triaxial test. This leads to an increased consumption of energy waves passing through the sample.

Figure 12 also depicts the effects of the cementing agent content on the variation in $\lambda$ with $\gamma_{\mathrm{d}}$ in the LCSG material, indicating that $\lambda$ decreases with an increased cementing agent content. As with other geotechnical materials, when the shear modulus of the LCSG material decreases, its damping ratio is expected to increase [17-19, 25]. The LCSG material can also be seen as a modified granular soil whose amount of cement has increased. The energy spent on samples with weak cementation should be greater than that spent on samples with strong cementation. This observation is in consistence with the results for CSC and CFSC under different curing ages obtained by Lang et al. [19].

3.4. Expression for Damping Ratio. Similar to the dynamic shear modulus in equation (10), the relationship between $\lambda$ and $\gamma_{\mathrm{d}}$ of the LCSG material was obtained as follows [34]:

$$
\frac{\lambda}{\lambda_{\max }}=\frac{a \bar{\gamma}_{\mathrm{d}}}{1+a \bar{\gamma}_{\mathrm{d}}} \text {. }
$$

Figure 13 shows the relationship between $\bar{\gamma}_{\mathrm{d}} / \lambda$ and $\bar{\gamma}_{\mathrm{d}}$ with varying cementing agent contents. Accordingly, the following equation can be derived:

$$
\frac{\bar{\gamma}_{\mathrm{d}}}{\lambda}=\frac{1}{\lambda_{\max }} \bar{\gamma}_{\mathrm{d}}+\frac{1}{a \lambda_{\max }},
$$

where $\lambda_{\max }$ is the maximum damping ratio, $1 / \lambda_{\max }$ is the slope of the line describing the relationship between $\bar{\gamma}_{\mathrm{d}} / \lambda$ and $\bar{\gamma}_{\mathrm{d}}$, and $1 / a \lambda_{\max }$ is the intercept of that line.

The maximum damping ratios $\lambda_{\max }$ of the rockfill [38] and LCSG materials with cementing agent contents of 40,60 , and $80 \mathrm{~kg} / \mathrm{m}^{3}$ are shown in Figure 14, where it can be 


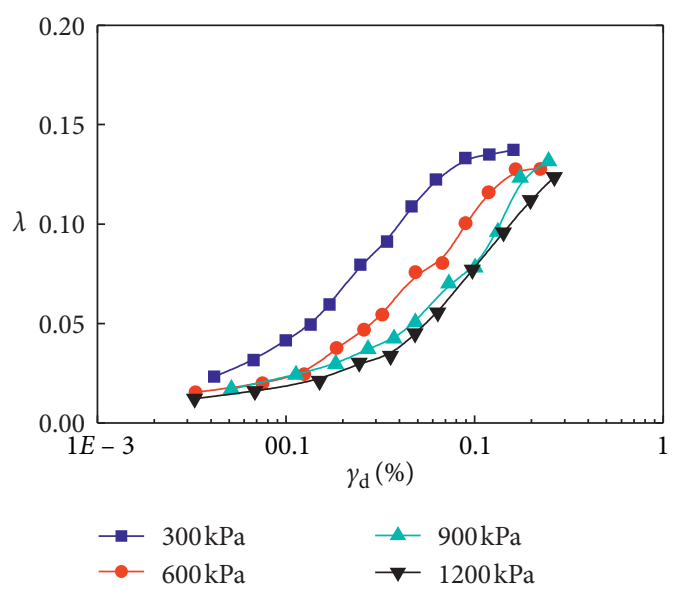

(a)

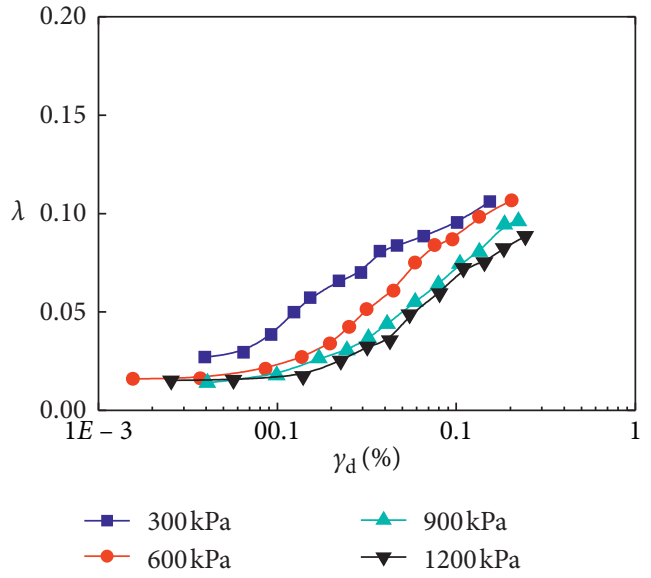

(b)

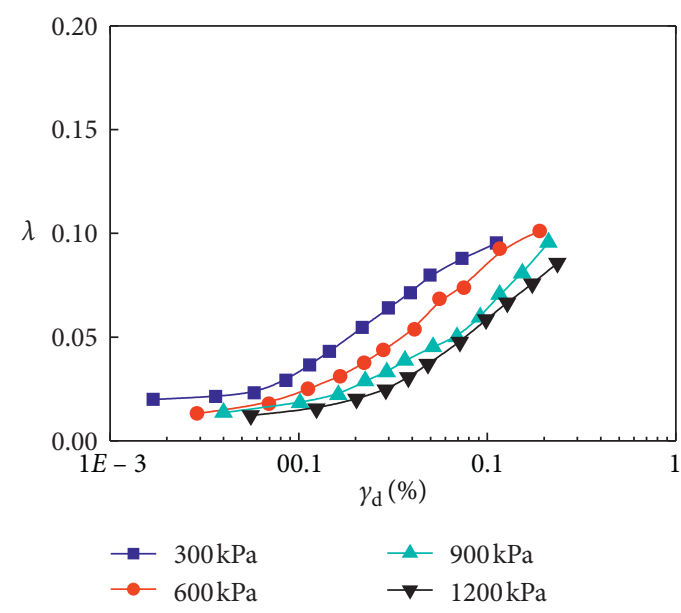

(c)

FIGURE 12: Damping ratio $\lambda$ of the LCSG material under different cementing agent contents and according to changes in dynamic shear strain. (a) $40 \mathrm{~kg} / \mathrm{m}^{3}$. (b) $60 \mathrm{~kg} / \mathrm{m}^{3}$. (c) $80 \mathrm{~kg} / \mathrm{m}^{3}$.

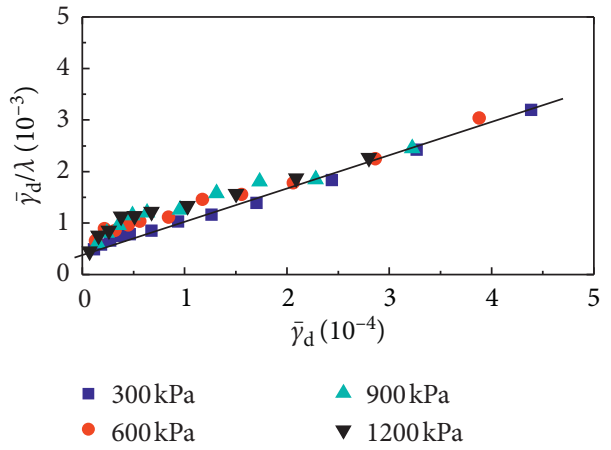

(a)

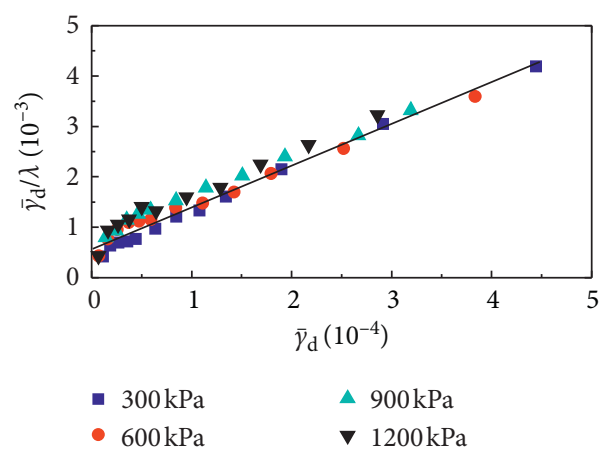

(b)

FIgURE 13: Continued. 


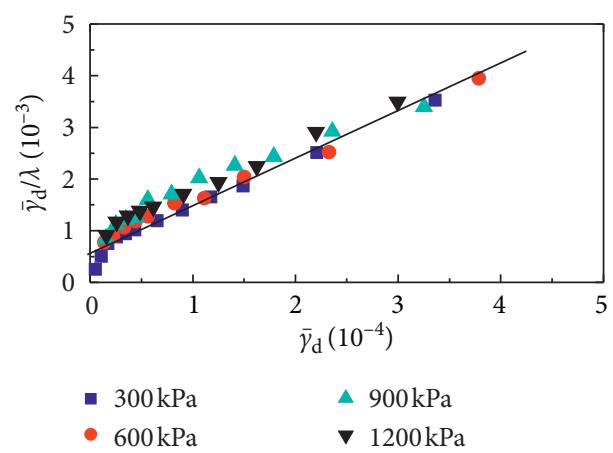

(c)

Figure 13: Relation between $\bar{\gamma}_{\mathrm{d}} / \lambda$ and $\bar{\gamma}_{\mathrm{d}}$ for varying cementing agent contents. (a) $40 \mathrm{~kg} / \mathrm{m}^{3}$. (b) $60 \mathrm{~kg} / \mathrm{m}^{3}$. (c) $80 \mathrm{~kg} / \mathrm{m}^{3}$.

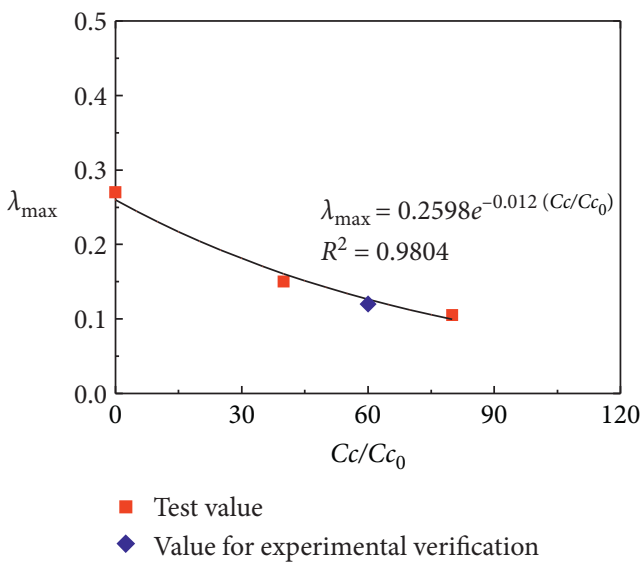

Figure 14: Relation of $\lambda_{\max }$ and the cementing agent content.

observed that, as $C c$ increases, $\lambda_{\max }$ also increases, which is similar to the results for CSC and CFSC under different curing ages obtained by Lang et al. [19]. Therefore, the following empirical equation was used to fit the relationship between $\lambda_{\max }$ and $C c$ of the rockfill and the LCSG material with cementing agent contents of 40 and $80 \mathrm{~kg} / \mathrm{m}^{3}$ :

$$
\lambda_{\max }=c e^{\mathrm{d}\left(C c / C c_{0}\right)}
$$

where parameters $c$ and $d$ are the fitting coefficients of the relationship between $\lambda_{\max }$ and $C c$. Here, $c$ represents the growth for $\lambda_{\max }$ with an increase in $C c$, and $\mathrm{d}$ represents the value of $\lambda_{\max }$ when $C c$ is 0 . Equation (15) was used to fit the relationship between $\lambda_{\max }$ and cementing agent content $C c$ in Figure 14, which shows that $c$ and $d$ are 0.2598 and -0.012 , respectively.

To verify the accuracy of these expressions, the experimental results for the LCSG material with the cementing agent content of $60 \mathrm{~kg} / \mathrm{m}^{3}$ were compared with the calculated results shown in Figure 14. The calculated results fit the experimental results well, thereby demonstrating that equation (15) can be used to describe $\lambda_{\max }$ of the LCSG material as a function of the cementing agent content.

By substituting $\bar{\gamma}_{\mathrm{d}}=\gamma_{\mathrm{d}}\left(\sigma_{3}+\mathrm{Pa} / \mathrm{Pa}\right)^{n-1}$ and equation (9) into equation (13), the damping ratio of the LCSG material

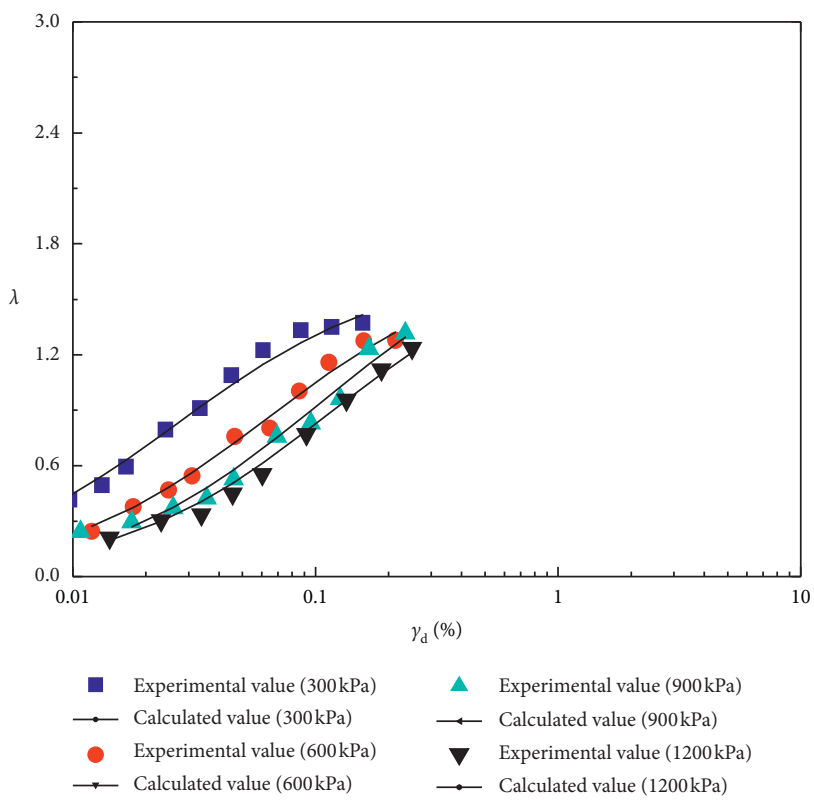

Figure 15: Experimental damping ratio results and their corresponding calculated values.

according to the cementing agent content and mean effective confining pressure can be determined as

$$
\lambda=\frac{\gamma_{\mathrm{d}}\left[\left(\sigma_{3}+\mathrm{Pa}\right) / \mathrm{Pa}\right]^{n_{0} e^{m\left(C c / C c_{0}\right)}}-1}{\left(1 / a \lambda_{\max }\right)+\left(\gamma_{\mathrm{d}} / \lambda_{\max }\right)\left[\left(\sigma_{3}+\mathrm{Pa}\right) / \mathrm{Pa}\right]^{n_{0} e^{m\left(C c / C c_{0}\right)-1 .}}}
$$

The parameters for equation (16) can be determined for the LCSG material cementing agent contents of 40 and $80 \mathrm{~kg} / \mathrm{m}^{3}$ and for rockfill [38]. In order to verify the applicability of equation (16), the test results of the damping ratio under different shear strains and mean effective confining pressures for the LCSG material with a cementing agent content of $60 \mathrm{~kg} / \mathrm{m}^{3}$ were used, and the calculated results are shown in Figure 15. The results show that equation (16) can effectively reflect the variation law of the damping ratio with shear strain, similar to granular soil and cement-treated clay $[17-19,25]$, and it can also fit the experimental results well, thus demonstrating that equation 
(16) can be used to describe the dynamic damping ratio of the LCSG material as a function of a cementing agent content of $60 \mathrm{~kg} / \mathrm{m}^{3}$. Similar to equation (12) for dynamic shear modulus, this validation also shows that equation (16) for the damping ratio is also suitable for the LCSG material under different cementing agent contents and for coarsegrained soils.

\section{Conclusion}

In this study, the small-strain dynamic shear modulus $G_{\mathrm{d}}$ and dynamic damping ratio $\lambda$ of the LCSG material based on cementing agent content and mean effective confining pressure were systematically investigated via a series of dynamic triaxial tests. The conclusions based on the results of the tests are as follows.

$G_{\mathrm{d}}$ of the LCSG material increased with an increase in the cementing agent content (i.e., the formation of hydration products) and confining pressure (i.e., compaction degree). The variation in $G_{\mathrm{d}}$ decreased with increasing shear strain $\gamma_{\mathrm{d}}$. $\lambda$ of the LCSG material decreased with increasing confining pressure and cementing agent content. It increased almost linearly with $\gamma_{\mathrm{d}}$ ranging from $10^{-3}$ to $10^{-2}$ and then increased rapidly thereafter. This is likely because a weakly cemented and loosely compacted LCSG material can provide high energy dissipation of the vibration wave propagating through the specimen.

Prediction models for the dynamic shear modulus $G_{\mathrm{d}}$ and damping ratio $\lambda$ were then proposed and used to describe the dynamic mechanical properties of the LCSG material with a cementing agent content of less than $80 \mathrm{~kg} /$ $\mathrm{m}^{3}$ and a mean effective confining pressure lower than $1200 \mathrm{kPa}$, and then the dynamic mechanical properties of conventional sand and gravel materials were described.

The findings of this study could be of use in establishing a reasonable dynamic constitutive model of LCSG materials with different cementing agent contents, as well as promoting the application and utilization of LCSG materials in high dams, embankments, and other civil engineering projects and infrastructures.

\section{Data Availability}

The data used to support the findings of this study are available from the corresponding author upon request.

\section{Conflicts of Interest}

The authors declare that there are no actual or potential conflicts of interest regarding the publication of this paper.

\section{Acknowledgments}

This research was funded by The National Key Research and Development Program of China (2018YFC0406804); Basic Public Welfare Research Project of Zhejiang (LGF20E090002); the Belt and Road Special Foundation of the State Key Laboratory of Hydrology-Water Resources and Hydraulic Engineering (2019492111); the Natural Science Foundation of the Higher Education Institutions of Jiangsu
Province (18KJB130004); and the Natural Science Foundation of Jiangsu Province (SBK2019022365).

\section{References}

[1] J. M. Raphael, Optimum Gravity Dam, Rapid Construction of Concrete Dams, ASCE, New York, NY, USA, 1970.

[2] J. S. Jia, M. Lino, F. Jin, and C. Y. Zheng, "The cemented material dam: a new, environmentally friendly type of dam," Engineering, vol. 2, no. 4, pp. 490-497, 2016.

[3] Z. H. Zhao, "Research on compressive test of CSG material," Master thesis, North China University of Water Resources and Electric Power, Zhengzhou, China, 2014.

[4] L. L. Liu, J. X. He, and L. Liu, "Study on infuencing factors of compressive strength of gel sandy gravel materials and law," Concrete, vol. 3, pp. 77-80, 2013.

[5] L. Kongsukprasert, F. Tatsuoka, and M. Tateyama, "Several factors affecting the strength and deformation characteristics of cement-mixed gravel," Soils and Foundations, vol. 45, no. 3, pp. 107-124, 2005.

[6] S. M. Haeri, A. Hamidi, S. M. Hosseini, E. Asghari, and D. G. Toll, "Effect of cement type on the mechanical behavior of a gravely sand," Geotechnical and Geological Engineering, vol. 24, no. 2, pp. 335-360, 2006.

[7] M. Wu, B. Du, Y. Yao, and X. He, "An experimental study on stress-strain behavior and constitutive model of hardfill material," Science China Physics, Mechanics and Astronomy, vol. 54, no. 11, pp. 2015-2024, 2011.

[8] A. V. D. Fonseca, "Influence of voids-cement ration on stressdilatancy-strength behavior of artificially cemented sand," Journal of Geotechnical and Geoenvironmental Engineering, vol. 138, no. 1, pp. 100-109, 2012.

[9] D. Li, X. Liu, and X. Liu, "Experimental study on artificial cemented sand prepared with ordinary portland cement with different contents," Materials, vol. 8, no. 7, pp. 3960-3974, 2015.

[10] Y. Amini and A. Hamidi, "Triaxial shear behavior of a cementtreated sand gravel mixture," Journal of Rock Mechanics and Geotechnical Engineering, vol. 6, no. 5, pp. 455-465, 2014.

[11] Y. Yang, X. Li, X. Li, X. W. Guo, Y. L. Wu, and J. L. Zhao, "Shear strength and compression coefficient for conditioned sand subjected to earth chamber stress levels," Advances in Materials Science and Engineering, vol. 2018, Article ID 2531642, 11 pages, 2018.

[12] J. Yang, X. Cai, X. W. Guo, and J. L. Zhao, "Effect of cement content on the deformation properties of cemented sand and gravel material," Applied Sciences, vol. 9, no. 11, p. 2369, 2019.

[13] A. F. Cabalar and Z. Karabash, "Influence of cement type and sample preparation on the small-strain behaviour of sands," Arabian Journal for Science and Engineering, vol. 44, no. 10, pp. 8835-8848, 2019.

[14] C. R. I. Clayton and G. Heymann, "Stiffness of geomaterials at very small strains," Géotechnique, vol. 51, no. 3, pp. 245-255, 2001.

[15] X. Liu, D. Zou, J. Liu, C. Zhou, and B. Zheng, "Experimental study to evaluate the effect of particle size on the small strain shear modulus of coarse-grained soils," Measurement, vol. 163, pp. 1-15, Article ID 107954, 2020.

[16] M. Bayat and A. Ghalandarzadeh, "Stiffness degradation and damping ratio of sand-gravel mixtures under saturated state," International Journal of Civil Engineering, vol. 16, no. 10, pp. 1261-1277, 2018.

[17] W. Li, L. Lang, D. Wang, Y. Wu, and F. Li, "Investigation on the dynamic shear modulus and damping ratio of steel slag 
sand mixtures," Construction and Building Materials, vol. 162, pp. 170-180, 2018.

[18] P. Subramaniam, S. Banerjee, and T. Ku, "Shear modulus and damping ratio model for cement treated clay," International Journal of Geomechanics, vol. 19, no. 7, pp. 1-6, Article ID 06019010, 2019.

[19] L. Lang, F. D. Li, and B. Chen, "Small-strain dynamic properties of silty clay stabilized by cement and fly ash," Construction and Building Materials, vol. 237, pp. 1-11, 2020.

[20] Y. H. Wang and C. M. Mok, "Mechanisms of small-strain shear-modulus anisotropy in soils," Journal of Geotechnical and Geoenvironmental Engineering, vol. 134, no. 10, pp. 1516-1530, 2008.

[21] M. Payan, A. Khoshghalb, K. Senetakis, and N. Khalili, "Small-strain stiffness of sand subjected to stress anisotropy," Soil Dynamics and Earthquake Engineering, vol. 88, pp. 143151, 2016.

[22] K. Yao, Q. S. Chen, J. H. Ho, H. W. Xiao, and F. H. Lee, "Strain-dependent shear stiffness of cement-treated marine clay," Journal of Materials in Civil Engineering, vol. 30, no. 10, pp. 1-10, Article ID 04018255, 2018.

[23] K. Yao, Q. S. Chen, H. W. Xiao, Y. Liu, and F. H. Lee, "Smallstrain shear modulus of cement-treated marine clay," Journal of Materials in Civil Engineering, vol. 32, no. 6, pp. 1-12, Article ID 04020114, 2020.

[24] M. Bayat and A. Ghalandarzadeh, "Influence of depositional method on dynamic properties of granular soil," International Journal of Civil Engineering, vol. 17, no. 6, pp. 907-920, 2019.

[25] M. Bayat and A. Ghalandarzadeh, "Modified models for predicting dynamic properties of granular soil under anisotropic consolidation," International Journal of Geomechanics, vol. 20, no. 3, pp. 1-15, Article ID 04019197, 2020.

[26] S. Omae, "Dynamic properties of CSG," in Proceedings of the 4th International Symposium on Roller Compacted Concrete Dams, pp. 511-518, Madrid, Spain, November 2003.

[27] Y. Ming, X. Cai, X. W. Guo, and H. Fu, "Dynamic characteristic test on cemented sand and gravel material," Advances in Science and Technology of Water Resources, vol. 34, no. 1, pp. 49-52, 2014.

[28] H. Fu, S. S. Chen, H. Q. Han, and H. Ling, "Experimental study on static and dynamic properties of cemented sand and gravel," Chinese Journal of Geotechnical Engineering, vol. 37, no. 2, pp. 357-362, 2015.

[29] X. C. Zhang and H. Huang, "Experimental and theoretical investigation on dynamic performance of cemented sand and gravel material," Science of Advanced Materials, vol. 10, no. 7, pp. 979-988, 2018.

[30] SL678-2014, Technical Guideline for Cemented Granular Material Dams Particles, Ministry of Water Resources of the People's Republic of China, Beijing, China, 2014.

[31] SL237-1999, Specification of Soil Test, Ministry of Water Resources of the People's Republic of China, Beijing, China, 1999.

[32] China Communications Press, Technical Manual for Geotechnical Testing, China Communications Press, Geotechnical Engineering Department, Nanjing Hydraulic Research Institute, Beijing, China, 2003.

[33] Y. Ming, "Study on the dynamic properties of CSG material and the earthquake response behaviors of CSG dam," Master thesis, Hohai University, Nanjing, China, 2013.

[34] Y. R. Zheng and L. Kong, Geotechnical Plastic Mechanics, China Construction Industry Press, Beijing, China, 2010.
[35] H. Zhao and L. Ge, "Investigation on the shear moduli and damping ratios of silica gel," Granular Matter, vol. 16, no. 4, pp. 449-456, 2014.

[36] M. Payan, K. Senetakis, A. Khoshghalb, and N. Khalili, "Characterization of the small-strain dynamic behaviour of silty sands; contribution of silica non-plastic fines content," Soil Dynamics and Earthquake Engineering, vol. 102, pp. 232-240, 2017.

[37] A.-R. Kim, I. Chang, G.-C. Cho, and S.-H. Shim, "Strength and dynamic properties of cement-mixed Korean marine clays," KSCE Journal of Civil Engineering, vol. 22, no. 4, pp. 1150-1161, 2018.

[38] X. L. Lü, S. C. Chi, and Y. F. Jia, "Experimental study on dynamic deformation behavior of rockfill materials," Chinese Journal of Geotechnical Engineering, vol. 40, no. 9, pp. 1729-1735, 2018.

[39] B. O. Hardin and V. P. Drnevich, "Shear modulus and damping in soil: measurement and parameter effects," ASCE Soil Mechanics and Foundation Division Journal, vol. 98, no. 6, pp. 603-624, 1972. 